\title{
Exercise and hypertension: facts and uncertainties
}

\author{
Marleen A van Baak
}

In 1986 the World Health Organization (WHO) and the International Society of Hypertension (ISH) ${ }^{1}$ stated very tentatively that "increased physical activity is likely to reduce the risk of cardiovascular disease and is appropriate in mildly hypertensives". In 1991 a consensus document entitled Physical exercise in the management of hypertension was published by the World Hypertension League ${ }^{2}$ which concluded that exercise programmes can contribute to the management of hypertension, enhance the sense of well being, and may improve life expectancy. In 1992 the WHO/ ISH recommended lifestyle interventions such as weight reduction in the overweight, reduction of alcohol consumption, regular mild exercise in sedentary subjects, and salt restriction in the primary prevention of hypertension. ${ }^{3}$ In 1993 this was followed by a memorandum of the $\mathrm{WHO} / \mathrm{ISH}^{4}$ which stated that "it appears reasonable to advise that efforts to lower blood pressure by lifestyle modifications, including exercise, should normally precede any decision about the necessity of drug treatment of mild hypertension". At approximately the same time the US Joint National Committee on the Detection, Evaluation and Treatment of High Blood Pressure stated that physicians should vigorously encourage their hypertensive patients to adopt lifestyle modifications, including increased physical activity. The American College of Sports Medicine $^{6}$ recommended endurance exercise to reduce the incidence of hypertension in susceptible individuals and as the initial treatment strategy for individuals with mild to moderate hypertension. Since then, regular exercise has been widely advocated as an effective tool in the non-pharmacological treatment of hypertension and as an adjunct to its pharmacological treatment. Nevertheless, the evidence on which this view is based is sometimes challenged. ${ }^{78}$ In this review I will try to summarise the evidence for the role of exercise in the treatment of hypertension and also point out areas that are still uncertain. Dr M A van Baak.

Table 1 Classification of hypertension by resting blood pressure level

\begin{tabular}{llll}
\hline & $S B P(m m ~ H g)$ & & $D B P($ phase V) $(\mathrm{mm} \mathrm{Hg})$ \\
\hline Normotension & $<140$ & and & $<90$ \\
Mild hypertension & $140-180$ & and/or & $90-105$ \\
$\quad$ subgroup: borderline & $140-160$ & and/or & $90-95$ \\
Moderate and severe hypertension & $\geqslant 180$ & and/or & $\geqslant 105$ \\
Isolated systolic hypertension & $\geqslant 140$ & and & $<90$ \\
$\quad$ subgroup: borderline & $140-160$ & and & $<90$ \\
\hline
\end{tabular}

Reproduced from ref 4.

\section{Hypertension, cardiovascular risk and treatment}

Cardiovascular risk and blood pressure are positively correlated: the higher the blood pressure, the higher the risk of both stroke and coronary events. ${ }^{9}$ The current dividing line between normotension and hypertension lies at the level of blood pressure above which intervention has been shown to reduce the risk. ${ }^{4}$ The operational classification of hypertension by the World Health Organization/International Society of Hypertension is shown in table 1 .

The worldwide prevalence of hypertension is high. In most countries $15-25 \%$ of the adult population have raised blood pressure at screening. In most of these individuals blood pressure is mildly elevated. ${ }^{4}$ Lowering of blood pressure in patients with hypertension by pharmacological treatment significantly reduces the risk of stroke and myocardial infarction. ${ }^{10}$ The reduction of mortality from myocardial infarction is, however, less than predicted from observational studies. There is considerable suspicion that some of the drugs used may have adverse effects which partly counteract the benefits of the blood pressure reduction. ${ }^{8}$ Nonpharmacological blood pressure reductionfor instance, by regular exercise-therefore seems an attractive alternative. However, no prospective randomised trials have been performed to show that exercise training reduces cardiovascular morbidity and mortality in hypertensive patients.

The evidence that regular exercise has hypotensive efficacy comes from both epidemiological and intervention studies.

\section{Hypotensive efficacy of exercise} EVIDENCE FROM EPIDEMIOLOGICAL STUDIES Two large epidemiological studies in the United States (Harvard Alumni Study and Aerobics Center Longitudinal Study) seem to suggest that normotensive individuals with a low level of physical activity or fitness have an increased risk of developing hypertension in the future. ${ }^{11}{ }^{12}$ On the other hand, the results from epidemiological studies that have prospectively studied the association between changes in physical activity or physical fitness and changes in blood pressure are inconsistent, with the majority finding no attenuation of the increase in blood pressure in those who improved their fitness or increased their physical activity. ${ }^{7}$ Several, but not all, large epidemiological studies have reported an inverse 
Table 2 Meta-analyses of the effects of regular exercise training on resting blood pressure

\begin{tabular}{|c|c|c|c|}
\hline \multirow[b]{2}{*}{ Author(s) } & \multirow[b]{2}{*}{$\begin{array}{l}\text { Number of studies } \\
\text { included }\end{array}$} & \multicolumn{2}{|c|}{ Blood pressure effect } \\
\hline & & $\begin{array}{l}S B P \\
(m m \mathrm{Hg})\end{array}$ & $\begin{array}{l}\mathrm{DBP} \\
(\mathrm{mm} \mathrm{Hg})\end{array}$ \\
\hline Arroll and Beaglehole $(1992)^{14}$ & 13 & -6 & -7 \\
\hline Fagard $(1993)^{13}$ & 36 & $\begin{array}{r}-10 \\
-6 \\
-3\end{array}$ & $\begin{array}{ll}-8 & (\mathrm{HT}) \\
-7 & (\mathrm{BHT}) \\
-3 & (\mathrm{NT})\end{array}$ \\
\hline Kelley and McClellan $(1994)^{15}$ & $9^{\star}$ & $\begin{array}{l}-7 \\
-3\end{array}$ & $\begin{array}{ll}-6 & \text { (HT) } \\
-3 & \text { (control) }\end{array}$ \\
\hline Hagberg and Brown (1995) ${ }^{16}$ & 47 & -10.5 & $-8.6(\mathrm{HT})$ \\
\hline Halbert et al $(1997)^{17}$ & $27^{\star}$ & $\begin{array}{l}-4.0 \\
-4.8\end{array}$ & $\begin{array}{l}-3.6(\mathrm{HT}) \\
-3.1(\mathrm{NT})\end{array}$ \\
\hline Kelley $(1997)^{18}$ & $9^{\dagger}$ & -4.6 & -3.8 \\
\hline
\end{tabular}

* Only randomised controlled aerobic exercise studies. ${ }^{\dagger}$ Only randomised controlled dynamic resistance exercise studies. $\mathrm{HT}=$ hypertensive; $\mathrm{NT}=$ normotensive; $\mathrm{BHT}=$ borderline hypertensive.

relationship between blood pressure and level of physical activity or physical fitness. ${ }^{6}{ }^{13}$

Thus, although there is some evidence from epidemiological studies that regular exercise is associated with lower blood pressures, the evidence is by no means very strong. This may be inherent to this type of study where level of physical activity is very difficult to measure reliably and many confounding factors, such as diet and body weight, may play a part.

EVIDENCE FROM INTERVENTION STUDIES

In the 1990 s a number of meta-analyses and reviews of controlled intervention studies on the effects of regular exercise on blood pressure have been published. ${ }^{13-18}$ A summary of their results is shown in table 2 . The picture that emerges from these meta-analyses is quite clear: aerobic exercise training reduces resting systolic and diastolic blood pressure. The range of mean blood pressure reductions in the meta-analyses including only randomised trials $^{15}{ }^{17}$ tends to be smaller than in metaanalyses with less stringent inclusion criteria (4-5/3-4 $\mathrm{mm} \mathrm{Hg}$ versus 3-10/3-8 $\mathrm{mm} \mathrm{Hg}$; table 2). ${ }^{131416}$ In only one of the approximately 50 reviewed studies was an increase in (diastolic) blood pressure found. It has been shown that a reduction in diastolic blood pressure of $5-6 \mathrm{~mm} \mathrm{Hg}$ by pharmacological treatment is associated with a $42 \%$ reduction in the incidence of stroke and a $14 \%$ reduction in coronary heart disease. ${ }^{10}$

Ambulatory blood pressure is more closely related to hypertension-related target organ damage than casual resting blood pressure. ${ }^{19}$ Fagard $^{20}$ reviewed the studies in which the effect of exercise training on ambulatory blood pressure was studied. Since ambulatory blood pressure measurement is a relatively new technique, the number of studies is small $(n=10)$. Fagard concluded that daytime systolic and diastolic blood pressure seemed to be reduced in subjects with initially raised blood pressures. Night-time blood pressure in general did not change significantly. Hagberg and Brown ${ }^{16}$ stated that the reductions in ambulatory blood pressure tended to be smaller and less consistent than those for casual blood pressure, but felt this was not surprising in view of the inherent variability in ambulatory blood pressure recordings.

All the meta-analyses in table 2 report considerable heterogeneity in hypotensive efficacy between studies. A large number of known and unknown individual and environmental factors probably contribute to this heterogeneity. It is the challenge for the future to be able to predict which subjects under what environmental conditions will benefit from exercise intervention.

LEVEL OF BLOOD PRESSURE

It is not entirely clear whether the hypotensive effect of exercise training is different in hypertensive and normotensive subjects. Although a more pronounced blood pressure reduction by aerobic exercise in hypertensives is suggested by the analyses of Fagard ${ }^{13}$ and Hagberg and Brown, ${ }^{16}$ this finding was not confirmed by Halbert et al. ${ }^{17}$ On the other hand, in studies where normotensive and hypertensive subjects followed the same training programme, the blood pressure change was always greater in the hypertensive subjects than in the normotensive subjects. ${ }^{13}$

\section{AGE, SEX, AND ETHNICITY}

The effects of age, sex, and ethnicity on the blood pressure reducing efficacy of exercise training have been reviewed by Hagberg and Brown. ${ }^{16}$ They conclude that it is possible that middle-aged hypertensives reduce their blood pressure more with exercise training than both their younger and their older counterparts. In addition, they reported that Asians and Pacific Islanders may be more responsive than Caucasians. There are still insufficient data in Africans and African Americans to assess the hypotensive efficacy of exercise in these populations. Hagberg and Brown ${ }^{16}$ did not find evidence for a sex difference in responsiveness.

\section{AEROBIC OR RESISTANCE EXERCISE TRAINING}

The blood pressure lowering efficacy of dynamic resistance exercise training was addressed in the meta-analysis by Kelley. ${ }^{18}$ The number of studies $(n=9)$ with resistance exercise training as the only training modality is still much smaller than that using aerobic exercise. The number of studies in hypertensive subjects $(n=3)$ is even more limited. Nevertheless, the analysis showed reductions of resting systolic and diastolic blood pressure with dynamic resistance training comparable to those with aerobic exercise. In none of the reviewed studies was an increase in blood pressure found.

\section{EXERCISE MODALITY}

The aerobic exercise studies included in the above analyses used walking, jogging, cycling or a combination of these as training modalities. Guidelines for exercise training in the management of hypertension often mention other aerobic exercise forms such as swimming and cross country skiing. ${ }^{2-4}$ These recommendations have been extrapolated from the effects of other aerobic exercise forms and are not based on scientific evidence. There have been reports that blood pressure is increased in swimmers and cross country skiers compared with other athletes. ${ }^{21}{ }^{22}$ A recently published study by Tanaka et $a l^{23}$ fortunately shows that swimming training also lowers blood pressure in hypertensive individuals: a change of $-6 /-5 \mathrm{~mm} \mathrm{Hg}$ in supine blood pressure was found in the swimming group 
$(\mathrm{p}<0.05)$ compared with a change of $-2 /-3 \mathrm{~mm}$ $\mathrm{Hg}$ in the control group (NS). For cross country skiing such data are not available.

LONG TERM HYPOTENSIVE EFFICACY

The duration of the studies varied between four and 52 weeks. The meta-analysis by Hagberg and Brown ${ }^{16}$ suggests that most of the blood pressure reduction is already obtained within the first 10 weeks (or even more rapidly) of training, but that there may be a small additional effect $(2-2.5 \mathrm{~mm} \mathrm{Hg})$ with more prolonged duration of the exercise programme. Although there are no controlled studies lasting more than one year, there are also no indications that the hypotensive efficacy of exercise training gradually decreases.

EXERCISE INTENSITY, FREQUENCY AND DURATION Fagard $^{13}$ showed in his meta-analysis that weekly frequency, time per session, and exercise intensity did not contribute significantly to the variance in blood pressure response to training. Halbert et $a l^{17}$ also found no difference between programmes with training intensities of $\geqslant 70 \%$ and $<70 \% \mathrm{VO}_{2} \max$ or $>3$ and $\leqslant 3$ sessions per week. However, these authors indicate that the absence of a difference may be due to the limited heterogeneity of the included studies. Hagberg and Brown, ${ }^{16}$ on the other hand, who included more studies in their meta-analysis, did find a difference when studies with training intensities $<70 \%$ and $\geqslant 70 \% \quad \mathrm{VO}_{2} \max$ were compared (9.5/7 versus $6.8 / 6.8 \mathrm{~mm} \mathrm{Hg}$ ). However, it is doubtful whether a clear picture can be derived from these meta-analyses because other programme-related or group-related factors may bias the results. In studies where low and high intensity training programmes have been directly compared, the lower intensity programmes were either more effective $e^{24-26}$ or as effective $^{27} 28$ as the higher intensity programmes. It is worthwhile to study the relationship between exercise intensity and blood pressure reduction in more detail since low intensity training is associated with better adherence, lower musculoskeletal and cardiovascular risks, and is easier to implement.

\section{Mechanism of blood pressure lowering effect of exercise}

Several mechanisms have been proposed for the hypotensive efficacy of regular exercise. Studies by Japanese investigators suggest that the blood pressure reduction is initiated by volume depletion, induced by activation of the renal kallikrein-kinin, dopamine, and prostaglandin systems. ${ }^{29}{ }^{30} \mathrm{~A}$ subsequent reduction in sympathetic activity might be involved in the maintenance of the blood pressure reduction. ${ }^{30}$ Jennings, ${ }^{31}$ on the other hand, suggests that in Caucasians the primary events are an improvement of endothelium mediated vasodilatation ${ }^{32}$ and an increase in systemic arterial compliance in large vessels, ${ }^{33}$ although increases in arterial compliance are not always found..$^{35}$ This changes the afferent input to the arterial baroreceptors. ${ }^{36}$ The result could be a reduced sympathetic outflow to the renal bed ${ }^{37}$ which could counterbalance any tendency to an increase in blood volume and thus blood pressure. It is quite possible that the antihypertensive mechanism of exercise training differs among populations depending on the underlying hypertensive mechanism.

Kouamé $e t a l^{38}$ suggest that an attenuation of the cardiopulmonary baroreflex control of skeletal muscle vascular resistance after training at $70 \% \mathrm{VO}_{2} \mathrm{max}$ compared with training at $50 \%$ $\mathrm{Vo}_{2}$ max may contribute to the less pronounced hypotensive efficacy of higher intensity training compared with lower intensity training.

In addition to the direct effects of regular exercise on blood pressure described above, exercise training may also affect other factors that influence blood pressure such as diet, body weight, smoking, and alcohol consumption.

\section{Exercise and cardiovascular risk reduction in hypertension}

The ultimate goal of a recommendation of regular exercise to hypertensive subjects must be to reduce morbidity and mortality associated with hypertension. As stated above, to date there have been no prospective randomised trials to show that exercise training indeed reduces cardiovascular morbidity and mortality in hypertensive patients, and it is conceivable that other exercise induced effects offset the blood pressure lowering benefit of exercise in patients with hypertension. ${ }^{7}$ An important study in this respect, which at least suggests that hypertensives benefit from regular exercise, is the Aerobics Center Longitudinal Study by Blair and coworkers. ${ }^{39}$ In this study over 25000 men and over 7000 women aged 20-88 years were followed for an average of eight years. Men and women were categorised into three cardiorespiratory fitness levels based on the outcome of a maximal exercise test at baseline: low (least $20 \%$ ), moderate (next $40 \%$ ), and high (most fit 40\%). High fitness men with a systolic blood pressure $\geqslant 140 \mathrm{~mm} \mathrm{Hg}$ had a $32 \%$ lower all-cause mortality rate than low fitness men. An even larger difference $(81 \%)$ was found in women. However, no inverse gradient across fitness categories was seen for cardiovascular mortality in men with a systolic blood pressure of $\geqslant 140 \mathrm{~mm} \mathrm{Hg}$. In women the number of deaths from cardiovascular origin was too small to do this analysis. A raised blood pressure often clusters with other risk factors for cardiovascular disease. Blair et $a l^{39}$ showed that high fitness men with a combination of two or three risk factors (smoking, high serum cholesterol, raised blood pressure) had a $15 \%$ lower death rate than low fitness men without one of these risk factors. The difference in women with $50 \%$ was even more pronounced. Assuming that the level of cardiorespiratory fitness is, at least partly, related to the level of exercise, these results indicate that hypertensive subjects may also benefit from regular exercise, although a direct reduction of mortality from cardiovascular diseases could not be demonstrated in this study. ${ }^{39}$

It also remains unclear to what extent a reduction of blood pressure contributes to the beneficial effect of regular exercise in hypertension. Regular exercise is also known to affect other cardiovascular risk factors favourably, such 
as dyslipidaemia, insulin resistance, body weight, arterial compliance, left ventricular hypertrophy, or impaired cardiovascular reflex control. ${ }^{40}{ }^{41}$ On the other hand, even relatively small reductions of blood pressure such as those found during exercise training in hypertensive subjects may reduce the risk of stroke and other cardiovascular events considerably. ${ }^{3910}$

\section{Risks of exercise in hypertension}

Exercise has benefits but also risks. Fortunately the risk of the most serious complication of exercise-sudden death-is very low in the general population: estimations vary between 0 and 2 deaths per 100000 hours of exercise, ${ }^{42}$ although the risk increases in the presence of heart disease. ${ }^{43}$ It has been suggested that hypertension increases the risk of sudden death or exercise induced myocardial ischaemic events. ${ }^{7}$ On the other hand, regular exercise protects against sudden death or other cardiovascular events during exercise. ${ }^{7}$ It is therefore generally believed that the benefits of regular exercise exceed the risks even in patients with cardiovascular disease, especially when individuals are encouraged to avoid sudden high intensity exercise. ${ }^{63}$ Patients with hypertension are usually discouraged from participating in high intensity resistance training because of the excessive rise in blood pressure that may accompany such exercise. ${ }^{44}$ However, an increased risk associated with high intensity resistance training in hypertensive subjects has not been documented. ${ }^{6}$ The 26th Bethesda Conference of the American College of Sports Medicine and the American College of Cardiology recommends that the presence of mild hypertension in the absence of target organ damage or concomitant heart disease should not limit the eligibility for any competitive sports, whether dynamic or static. ${ }^{45}$

A pre-exercise screening is often recommended for hypertensive patients. ${ }^{273}$ In patients with more than a mildly raised blood pressure, drug treatment to reduce blood pressure will usually be initiated before the start of an exercise programme. ${ }^{6}$

\section{Combination of pharmacological treatment and exercise}

In patients with mild hypertension in whom non-drug lifestyle interventions do not result in adequate blood pressure reduction, and in patients with more severe hypertension, drug treatment will often be combined with an exercise advice. ${ }^{46}$ Several publications have reviewed the interaction between exercise and antihypertensive drug treatment. ${ }^{6}{ }^{6-49}$

There is convincing evidence that $\beta$-adrenoceptor blocking agents impair endurance exercise performance considerably; an average reduction of $40 \%$ is found with $\beta_{1+2}$-adrenoceptor blocking agents and a reduction of $20 \%$ with $\beta_{1}$-adrenoceptor blockers. ${ }^{47}$ Subjective exertion is also increased during exercise in hypertensive patients treated with beta blockers. ${ }^{47}$ Treatment with $\beta$-adrenoceptor blocking agents is therefore not attractive for physically active patients with hypertension, although some exercising patients may tolerate $\beta_{1}$-selective agents well. Other anti- hypertensive agents such as calcium antagonists, ACE inhibitors, and $\alpha$-adrenoceptor blocking agents usually have no significant effect on exercise performance. If significant effects are found, they always tend to be negative. ${ }^{48} 5051$ The effects of diuretics on exercise performance have not been studied very well. Diuretics may induce arrhythmias during exercise in the presence of hypokalaemia. ${ }^{46}$

There is very little information on the combined effects of drug treatment and exercise on blood pressure and results have been inconsistent. ${ }^{646479}$ It has been suggested that the reduction in blood pressure resulting from regular exercise may lead to lower dosages of antihypertensive drugs to control blood pressure, ${ }^{6}$ but in the literature very few data can be found to support this suggestion. Another important question is whether regular exercise still exerts its other beneficial effects such as increase in fitness, improvement of insulin sensitivity, lowering of blood lipids, in combination with drug treatment. This is an area where further studies are badly needed in order to provide a scientific basis for the combination of drug therapy and exercise training in hypertension.

\section{Exercise recommendations}

The recommendations for exercise in hypertensive individuals follow those for the general public $^{6435}$ : frequency 3-5 times per week; intensity $50-85 \% \quad \mathrm{VO}_{2} \mathrm{max}$; duration 20-60 minutes of continuous activity; mode of activity that uses large muscle groups and is rhythmic and aerobic in nature; resistance exercise (minimum of two days per week, 8-12 repetitions of the major muscle groups) is recommended as an integral part of each programme. In 1993 the American College of Sports Medicine added that exercise with an intensity of $40-70 \% \mathrm{Vo}_{2} \mathrm{max}$ appears to lower blood pressure as much as, or even more than, higher intensity exercise. Resistance exercise was not recommended as the only form of exercise for hypertensive individuals but rather as part of a well rounded fitness programme. ${ }^{6}$ Since then recommendations have further stressed the effectiveness of low to moderate activity ${ }^{43}$ and the value of relatively short lasting activities (intermittently, as short as $8-10 \mathrm{~min}-$ utes at a time) amounting to a total of $30 \mathrm{~min}$ utes or more over the course of most (and preferably all) days of the week outside formal exercise programmes. ${ }^{53}$

\section{Summary}

Regular exercise is recommended in the non-pharmacological treatment of hypertension. Intervention studies show that regular exercise lowers blood pressure. The average reduction of blood pressure in several metaanalyses of studies on the effects of aerobic exercise training in hypertensive patients ranges from $4 \mathrm{~mm} \mathrm{Hg}$ to $10 \mathrm{~mm} \mathrm{Hg}$. The smaller reductions are reported for the better designed studies. Individual (level of blood pressure, ethnicity) and environmental factors (type of exercise programme) may influence the hypotensive effectiveness of exercise programmes. Several hypotheses have been put 
forward to explain the reduction in blood pressure resulting from regular exercise. It is possible that the mechanism differs across populations because of differences in the underlying hypertensive condition. There are no long term studies showing that regular exercise lowers the risk of cardiovascular morbidity and mortality in hypertensive individuals. Nevertheless, epidemiological data suggest that a high fitness level protects against the influence of risk factors for cardiovascular mortality such as a raised blood pressure.

In many patients regular exercise will be advised as an adjunct to drug treatment. Data on the hypotensive effectiveness of exercise in such combinations are limited. Moreover, the interaction between antihypertensive agents and other potentially beneficial effects of regular exercise is often not known.

Despite the fact that a number of uncertainties with respect to the optimal exercise programme and the combined effects of drug treatment and exercise exist, there is sufficient direct and indirect evidence to encourage sedentary hypertensive patients to become more active in order to improve their health and fitness.

1 Memorandum from the WHO/ISH. Guides for the treatment of mild hypertension. Hypertension 1986;8:957-61.

2 World Hypertension League. Physical exercise in the management of hypertension: a consensus statement by the World Hypertension League. f Hypertens 1991;9:283-7.

3 WHO/ISH Guidelines Committee. Prevention of hypertension and associated cardiovascular disease: a 1991 statement. Clin Exp Hypertens $(A)$ 1992;14:333-41.

4 Guidelines Sub-Committee of the WHO/ISH Mild Hypertension Liaison Committee. 1993 guidelines for the tension Liaison Committee. 1993 guidelines for the World Health Organization/International Society of Hypertension Meeting. f Hypertens 1993;11:905-18.

5 Joint National Committee on Detection, Evaluation, and Treatment of High Blood Pressure. Report V. Arch Intern Med 1993;153:154-84.

6 American College of Sports Medicine. Physical activity, physical fitness, and hypertension. Med Sci Sports Exerc 1993;25:i-x.

7 Puddey IB, Cox K. Exercise lowers blood pressure - sometimes? Or did Pheidippides have hypertension? $\mathcal{F}$ Hypertens 1995;13:1229-33.

8 Chalmers J. The treatment of hypertension. Br f Clin Pharmacol 1996;42:29-35.

9 MacMahon S, Peto R, Cutler J, et al. Blood pressure, stroke and coronary heart disease. Part 1: Prolonged differences in blood pressure: prospective observational studies corrected for the regression dilution bias. Lancet 1990;335:765-74.

10 Collins R, Peto R, MacMahon S, et al. Blood pressure, stroke and coronary heart disease. Part 2: Short-term reductions in blood pressure; overview of randomised drug trials in their blood pressure; overview of randomised drug trial

11 Paffenbarger RS, Wing AL, Hyde RT, et al. Physical activity and incidence of hypertension in college alumni. Am $\mathcal{F} E p i-$ demiol 1983;117:245-57.

12 Blair SN, Goodyear NN, Gibbons LW, et al. Physical fitness and incidence of hypertension in healthy normotensive men and women. $\mathscr{F A M A}$ 1984;252:487-90.

13 Fagard RH. Physical fitness and blood pressure. 7 Hypertens 1993;11(Suppl 5):S47-S52.

14 Arroll B, Beaglehole R. Does physical activity lower blood pressure? A critical review of the clinical trials. 7 Clin Epidemiol 1992;45:439-47.

15 Kelley G, McClellan P. Antihypertensive effects of aerobic exercise. A brief meta-analytic review of randomized controlled trials. Am fHypertens 1994;7:115-9.

16 Hagberg JM, Brown MD. Does exercise training play a role in the treatment of essential hypertension? $\mathcal{f}$ Cardiovasc in the treatment of $1995 ; 2: 296-302$.

17 Halbert JA, Silagy CA, Finucane P, et al. The effectiveness of exercise training in lowering blood pressure: a metaanalysis of randomized controlled trials of 4 weeks longer. F Hum Hypertens 1997;11:641-9.

18 Kelley G. Dynamic resistance exercise and resting blood pressure in adults: a meta-analysis. $\mathcal{F}$ Appl Physiol 1997;82 $1559-65$

19 Pickering TG, Devereux RB. Ambulatory monitoring of blood pressure as a predictor of cardiovascular risk. $A m$ Heart f 1987;114:925-8.

20 Fagard RH. The role of exercise in blood pressure control: supportive evidence. F Hypertens 1995;13:1223-7.

21 Marti B. Physische Aktivität und Blutdruck. Eine epidemiologische Kurzreview des primärpräventiven Effekts von körperlich-sportlicher Betätigung. Schweiz Rundschau Med 1992;81:473-9.

22 Jennings GLR. Exercise and blood pressure: walk, run or swim? F Hypertens 1997;15:567-9.

23 Tanaka H, Bassett Jr DR, Howley ET, et al. Swimming training lowers the resting blood pressure in individuals with hypertension. F Hypertens 1997;15:651-7.

24 Hagberg JM, Montain SJ, Martin WH, et al. Effect of exercise training on 60-69-year-old persons with essential hypertension. Am 7 Cardiol 1989;64:348-53.

25 Matsusaki $M$, Ikeda $M$, Tashiro E, et al. Influence of workload on the antihypertensive effect of exercise. Clin Exp Pharmacol Physiol 1992;19:471-9.

26 Rogers MW, Probst MM, Gruber JJ, et al. Differential effects of exercise training intensity on blood pressure and cardiovascular responses to stress in borderline hypertensive humans. F Hypertens 1996;14:1369-75.

27 Roman O, Camuzzi AL, Villalon E, et al. Physical training program in arterial hypertension: a long-term prospective follow-up. Cardiology 1981;67:230-43.

28 Tashiro E, Miura S, Koga M, et al. Crossover comparison between the depressor effects of low and high work-rate exercise in mild hypertension. Clin Exp Pharmacol Physiol 1993;20:689-96.

29 Arakawa K. Antihypertensive mechanism of exercise. $\mathcal{F}$ Hypertens 1993;11:223-9.

30 Miura S, Tashiro E, Sakai T, et al. Urinary kallikrein activity is increased during the first few weeks of exercise training in essential hypertension. 7 Hypertens 1994;12:815-23.

31 Jennings GLR. Exercise and blood pressure: walk, run or swim? f Hypertens 1997;15:567-9.

32 Kingwell BA, Sherrard B, Jennings GL, et al. Four weeks of cycle training increases basal production of nitric oxide from the forearm. Am F Physiol 1997;272:H1070-7.

33 Cameron JD, Dart AM. Exercise training increases total systemic arterial compliance in humans. Am $\mathcal{f}$ Physiol 1994;266:H693-701.

34 Wijnen JAG, Kuipers H, Kool MJF, et al. Vessel wall properties of large arteries in trained and sedentary subjects. erties of large arteries in trained and seden
Basic Res Cardiol 1991;86 (Suppl 1):25-9.

35 Wijnen JA, Kool MJ, Kooman JP, et al. Vessel wall properties of large arteries and endurance training. $\mathcal{F}$ Hypertens 1993; 1 (Suppl 5):S88-9.

36 Kingwell BA, Cameron JD, Gillies KJ, et al. Arterial compliance may influence baroreflex function in athletes and hypertensives. Am F Physiol 1995;258:H411-8.

37 Meredith IT, Friberg P, Jennings GL, et al. Exercise training owers resting renal but not cardiac sympathetic activity in human. Hypertension 1991;18:575-82.

38 Kouamé N, Nadeau A, Lacourcière Y, et al. Effects of different training intensities on the cardiopulmonary baroreflex control of forearm vascular resistance in hypertensive subjects. Hypertension 1995;25:391-8.

39 Blair SN, Kampert JB, Kohl III HW, et al. Influences of cardiorespiratory fitness and other precursors on cardiovascular disease and all-cause mortality in men and women. cular disease and all-cause

40 Gilders RM, Dudley GA. Endurance exercise training and treatment of hypertension. Sports Med 1992;13:71-7.

41 Jennings GLR. Mechanisms for reduction of cardiovascula risk by regular exercise. Clin Exp Pharmacol Physiol 1995;22:209-11.

42 Fletcher GF, Balady G, Blair SN, et al. Statement on exercise: benefits and recommendations for physical activity programs for all Americans. A statement for health professionals by the Committee on Exercise and Cardiac Rehabilitation of the Council on Clinical Cardiology, American Heart Association. Circulation 1996;94:857-62.

43 Fletcher GF, Balady G, Froelicher VF, et al. Exercise standards. A statement for health care professionals from the American Heart Association. Circulation 1995;91:580-615.

44 MacDougall JD, Tuxen D, Sale DG, et al. Arterial blood pressure response to heavy resistance exercise. $\mathcal{F} A p p l$

45 Kaplan NM, Deveraux RB, Miller Jr HS. Systemic hypertension. Med Sci Sports Exerc 1994;26 (Suppl):S268-70.

46 Chick TW, Halperin AK, Gacek EM. The effect of antihypertensive medications on exercise performance: a review. Med Sci Sports Exerc 1988;20:447-54.

47 Van Baak MA. $\beta$-Adrenoceptor blockade and exercise: an update. Sports Med 1988;4:209-25.

48 Van Baak MA. Hypertension, $\beta$-adrenoceptor blocking agents and exercise. Int f Sports Med 1994;15:112-5.

49 Peel C, Mosberg KA. Effects of cardiovascular medications on exercise responses. Phys Ther 1995;75:387-96.

50 Van Baak MA, Mooij JM, Wijnen JA, et al. Submaximal endurance exercise performance during enalapril treatment in patients with essential hypertension. Clin Pharmacol Ther 1991;50:221-7.

51 Tomten SE, Kjeldsen SE, Nilsson S, et al. Effect of $\alpha_{1}$-adrenoceptor blockade on maximal $\mathrm{VO}_{2}$ and endurance capacity in well-trained athletic hypertensive men. $\mathrm{Am} \mathcal{f}$ Hypertens 1994;7:603-8.

52 American College of Sports Medicine. The recommended quantity and quality of exercise for developing and healthy adults. Med Sci Sports Exerc 1990;22:265-74.

53 Pate RR, Pratt M, Blair SN, et al. Physical activity and pubic health. A recommendation from the Centers of Disease Control and Prevention and the American College of Sports Medicine. FAMA 1995;273:402-7. 